\title{
Tissue-engineered triphasic ceramic coated hydroxyapatite induced bone formation and vascularization at an extraskeletal site in a rat model
}

\author{
MANITHA B NAIR, H K VARMA, P V MOHANAN and ANNIE JOHN* \\ Biomedical Technology Wing, Sree Chitra Tirunal Institute for Medical Sciences and Technology, \\ Poojappura, Trivandrum 695 012, India
}

MS received 30 July 2009

\begin{abstract}
Tissue-engineered bone regeneration has attracted much attention because of its high clinical demand for restoration of injured tissues. In the present study, we have evaluated the capability of bare (without cells) and tissue-engineered (with osteogenic-induced rat Mesenchymal Stem Cells (MSCs)) bioactive ceramics such as hydroxyapatite (HA) and triphasic ceramic-coated hydroxyapatite (HASi) to mediate vascularisation and osteoinduction at an extraskeletal site of rat model. The viability, proliferation and osteogenic differentiation of MSCs on the scaffolds were assessed in vitro and thereby established the capability of HASi in providing a better structural habitat than HA. The vascular invasion was relatively low in bare and tissueengineered $\mathrm{HA}$ at 2 and 4 weeks. Interestingly, the implantation site was well vascularised with profuse ingrowth of blood capillaries in HASi groups, with preference for tissue-engineered HASi groups. Similarly, neo-osteogenesis studies were shown only by tissue-engineered HASi groups. The ingrowth of numerous osteoblast-like cells was seen around and within the pores of the material in bare HASi and tissue-engineered HASi groups (very low cellular infiltration in bare HA groups), but there was no osteoid deposition. The positive impact in forming bone in tissue-engineered HASi groups is attributable to the scaffold and to the cells, with the first choice for scaffold because both HA and HASi were engineered simultaneously with the cells from same source and same passage. Thus, highly porous interconnected porous structure and appropriate chemistry provided by HASi in combination with osteogenic-induced MSCs facilitated better vascularisation that lead to neo-osteogenesis.
\end{abstract}

Keywords. Bone formation; hydroxyapaite; rat model; vascularization.

\section{Introduction}

Bone is one of the most frequently transplanted tissues and its current demands are far outpacing the supply. An ideal bone substitute should simulate an autograft in its characteristics of being osteoconductive and osteointegrative, so that it can unite with host bone without fibrous tissue formation and inflammation. In addition, autograft contains viable osteoprogenitor cell pool that makes it osteoinductive (Kruyt et al 2004). Thus the current strategy is focused on tissue engineering, an osteoconductive material seeded with osteogenic cells, which has the potential to become an alternative to autografts (Salgado et al 2004). However, the cells in the constructs should survive and function after implantation, which in turn is dependent on the vascularisation potential of material at the vicinity of defect site (Kruyt et al 2003). Therefore the selection of a material, which can induce

\footnotetext{
*Author for correspondence

(karippacheril@gmail.com; ajkari@sctimst.ac.in)
}

bone formation and vascularisation, is a major challenge encountered in the field of bone tissue engineering.

Hard skeletal tissue is a complex composite consisting of cells embedded within a mineralized organic matrix with a structural similarity to hydroxyapatite (HA). On account of this similarity, synthetic bioactive ceramic like HA has been extensively used as a skeletal replacement material with no systemic toxicity or immunological reactions (Hench and Wilson 1993). Apart from calcium and phosphorous, substitutions of various other elements occur at trace level in bone mineral and among these, the significant role of silicon $(\mathrm{Si})$ in the growth and development of bone has been reported (Carlisle 1970). The incorporation of $\mathrm{Si}$ into the composition of bioactive ceramics becomes of great interest because of their ability to nucleate the precipitation and formation of a calcium phosphate layer on the implant surface leading to enhanced bone formation (Porter et al 2004). By considering these observations, bioactive ceramic, viz., triphasic ceramiccoated hydroxyapatite (HASi), having the properties of both HA and silica has been utilized in this study. The physico-chemical characterization and preliminary cyto- 
compatibility studies of HASi with goat and human bone marrow-derived mesenchymal stem cells were reported elsewhere (Nair et al 2008a, b; John et al 2008).

The most preferred and widely used cell source for bone tissue engineering is bone marrow-derived mesenchymal stem cells (BMSCs). They are multipotent capable of forming various tissues including bone, cartilage, muscle, fat and tendon (Pittenger et al 1999). The tissuespecific differentiation of BMSCs is dependent on the matrix or local environment in which MSC resides (Caplan 1991). So when MSCs are cultured in a medium with dexamethasone, L-ascorbic acid and $\beta$-glycerophosphate, they differentiate into an osteogenic lineage and form the mineralized tissue (Takahashi et al 2005). For tissue engineering applications, these cells can be administered by soaking the scaffold in fresh bone marrow (Burwell 1964) or after culture expansion (Goshima 1991). Among them, the latter approach has been shown to be far superior (Kruyt et al 2003).

In the present study, we have evaluated the ability of tissue-engineered bioactive ceramics in comparison with bare material to facilitate vascularisation and to induce bone at an extraskeletal site of rat model.

\section{Materials and methods}

\subsection{Materials}

Indigenously prepared hydroxyapatite (HA) and triphasic ceramic (calcium silicate, tricalcium phosphate and hydroxyapatite) coated hydroxyapatite (HASi) were used for the study. For synthesizing HASi, HA blocks were prepared and dipped in silica sol with the hypothesis that silicon ions will incorporate into HA as an outer coating layer, while the main core of HASi remains as HA. The major (core) phase of HASi is hydroxyapatite while the outer coating layer contains peaks for hydroxyapatite $\left(\mathrm{Ca}_{5}\left(\mathrm{PO}_{4}\right)_{3}(\mathrm{OH})\right), \beta$-tricalcium phosphate $\left(\mathrm{Ca}_{3}\left(\mathrm{PO}_{4}\right)_{2}\right)$ and calcium silicate $\left(\mathrm{Ca}_{2} \mathrm{SiO}_{4}\right)$. The core of HASi is polycrys- talline and has clear grain boundary characteristics while the outer coating layer is porous, less crystalline and has no clear grain and grain boundary. This is due to Si-rich liquid phase formation, which has penetrated to a depth of about $1 \mathrm{~mm}$. HA and HASi are interconnected porous in nature with pore size in the range of 50-500 $\mu \mathrm{m}$ (figure 1). The bulk density of HA was approximately $0.8 \mathrm{~g} / \mathrm{cc}$ indicating $70 \%$ porosity, while the bulk density of HASi was approximately $1.04 \mathrm{~g} / \mathrm{cc}$ representing $67 \%$ porosity (John 2008; Nair 2008).

\subsection{Material preparation}

Hydroxyapatite powder was synthesized by a wet precipitation method involving calcium nitrate and ammonium dihydrogen phosphate in the stoichiometric proportion at a $\mathrm{pH}$ of 11 and a temperature of $80^{\circ} \mathrm{C}$. The precipitated HA powder was freeze-dried and washed with distilled water to get rid of surface impurities such as nitrate and ammonium ions. HA powder having particle size less than $125 \mu \mathrm{m}$ was mixed with aqueous solution of polyvinyl alcohol and gluteraldehyde solution and stirred for $30 \mathrm{~min}$. To the resulting frothy slurry, benzoyl peroxide dispersed in benzene and $N, N$-dimethyl aniline was added and stirred for thorough mixing. The resulting frothy and viscous slurry was poured into plastic moulds and allowed to dry at room temperature. After drying, the blocks were biscuit fired at $300^{\circ} \mathrm{C}$ for $1 \mathrm{~h}$ to remove the binder and then sintered at temperature between 1100 and $1300^{\circ} \mathrm{C}$ for $1 \mathrm{~h}$ to get strong but porous ceramics. Hydroxyapatite blocks prepared by the above process were dipped in silica sol prepared by the hydrolysis of tetraethyl orthosilicate (TEOS) in ethanol-water system for $1 \mathrm{~min}$. The resultant coated HA ceramic was sintered at $1200^{\circ} \mathrm{C}$ for $2 \mathrm{~h}$ to get a coating of silica over HA. Hydroxyapatite without coating, but synthesized under the same conditions, was used as the control for all the experiments. The materials were polished to get a size of $1 \mathrm{~cm}$ (length) $\times 1 \mathrm{~mm}$ (breadth) $\times 1 \mathrm{~mm}$ (thickness) and
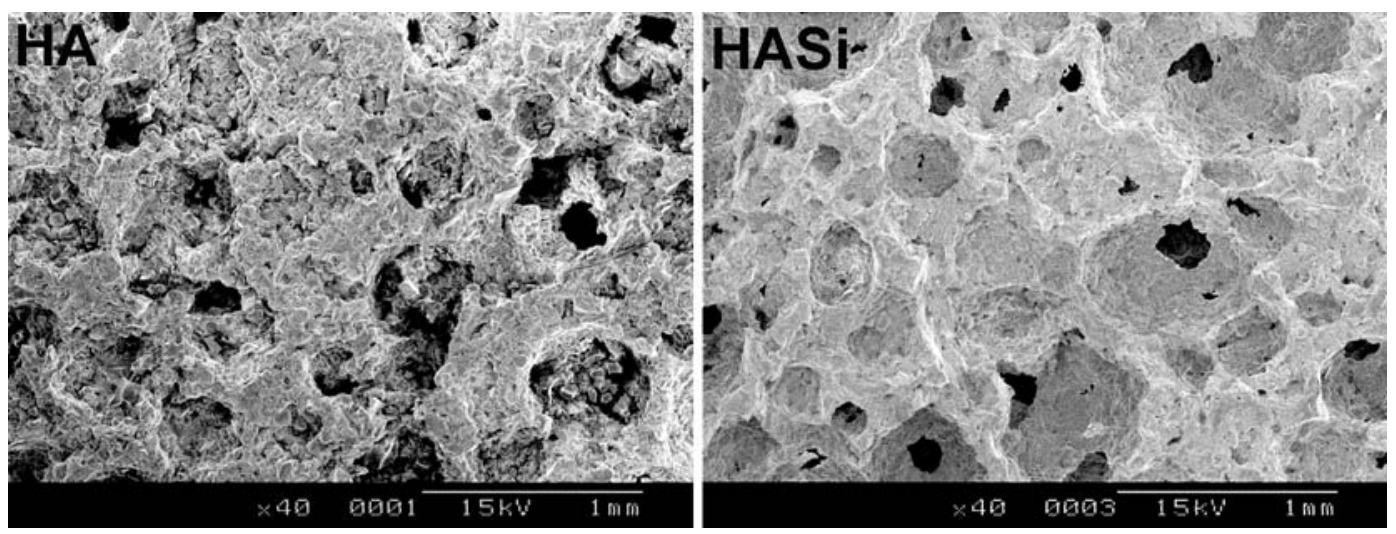

Figure 1. Scanning electron micrographs showing interconnected structure of HA and HASi having pore size in range of $50-500 \mu \mathrm{m}$. 
subjected to ultrasonic cleaning for the complete removal of fine powders adhered over the surface. Prior to cell seeding, the materials were steam sterilized and conditioned by incubating in $\alpha$-minimal essential medium $\left(\alpha\right.$-MEM) with $10 \%$ fetal bovine serum (FBS) at $37^{\circ} \mathrm{C}$ for $24 \mathrm{~h}$.

\subsection{Cell culture}

Wistar rats of average weight $200-300 \mathrm{~g}$ were aseptically prepared and draped in a sterile fashion. After they were euthanized by administration of chloroform, their muscles were separated; femur and tibia bone were retrieved and collected in phosphate-buffered saline (PBS) with double dose of antibiotics (200 units/ml of penicillin and $200 \mu \mathrm{g} / \mathrm{ml}$ of streptomycin: Gibco, India). The two ends of femur and tibia were cut and the bone marrow was flushed using a syringe with 18-gauge needle, which contains growth medium ( $\alpha$-MEM with $10 \%$ FBS) and doubledose antibiotics. The clumps of cells were gently broken and centrifuged at $500 \mathrm{~g}$ for $10 \mathrm{~min}$. The cell pellet was plated in $25 \mathrm{~cm}^{2}$ flask (Nunc, India) having $5 \mathrm{ml}$ growth medium and single dose of antibiotics and incubated at $37^{\circ} \mathrm{C}$ in humid atmosphere and $5 \% \mathrm{CO}_{2}$. The medium was changed after 3 days to remove non-adherent cells and subsequently renewed twice a week. After 10 days in primary culture, the adherent BMSCs were released with $0.25 \%$ trypsin-EDTA (Gibco, India) and centrifuged at $300 \mathrm{~g}$ for $10 \mathrm{~min}$. BMSCs of passage number 2-3 were selected for all in vitro and in vivo experiments.

\subsection{Fabrication of tissue-engineered constructs (in vitro)}

BMSCs were seeded $\left(1 \times 10^{5}\right.$ cells/material $)$ on all sides of conditioned HA and HASi placed in 48 well plates (Nunc, India) under static condition. After being incubated at $37^{\circ} \mathrm{C}$ for 30 min to allow cell attachment, $\alpha$ MEM with $10 \%$ FBS was added for $24 \mathrm{~h}$, which was followed by osteogenic medium ( $\alpha$-MEM supplemented with $15 \%$ FBS, $10 \mathrm{mM} \beta$-glycerophosphate, $10^{-8} \mathrm{M}$ dexamethasone and $0.05 \mathrm{mg} / \mathrm{ml} \mathrm{L-ascorbic} \mathrm{acid} \mathrm{(Sigma} \mathrm{che-}$ micals) to induce the differentiation of rBMSCs into osteogenic lineage. The tissue-engineered constructs were maintained for 7 days.

\subsection{Evaluation of tissue-engineered constructs (in vitro)}

2.5a Cell morphology: The morphology of osteogenicinduced BMSCs was visualized on day 7 by scanning electron microscopy. The cell-cultured materials were washed with PBS, fixed in $1 \%$ gluteraldehyde in Sorensen phosphate buffer, dehydrated in a graded ethanol series, critically point dried (Hitachi HCP-2), gold coated in an ion sputter (Hitachi E101) and examined under scanning electron microscope (Hitachi 2500).

2.5b Biochemical assays: The cell-cultured materials were washed with $\mathrm{PBS}$ twice and kept at $-80^{\circ} \mathrm{C}$ until analysis. The frozen cell constructs were thawed for $20 \mathrm{~min}$ on ice and lysed with $1 \%$ Triton X-100 for $50 \mathrm{~min}$ with sonication for $10 \mathrm{~min}$. The cell lysate was used for determining cell viability, proliferation and osteogenic differentiation simultaneously.

2.5c Cell viability: The cell viability was determined through the total activity of lactate dehydrogenase (LDH) in the cell lysate using LDH reaction buffer (Cytotox96 kit, Promega, USA). An aliquot of cell lysate $(50 \mu \mathrm{l})$ was mixed with $\mathrm{LDH}$ substrate $(50 \mu \mathrm{l})$ at room temperature and the enzymatic reaction was stopped after $30 \mathrm{~min}$ with $0.1 \mathrm{M}$ acetic acid $(50 \mu \mathrm{l})$. The absorbance was read at $492 \mathrm{~nm}$ (Erba Chem-7). The absorbance (OD values) was correlated with cell viability using a calibration line constructed with increasing concentrations of cells.

2.5d Alkaline phosphatase activity: Alkaline phosphatase activity was measured based on the hydrolysis of $p$-nitrophenyl phosphate (sigma) to $p$-nitrophenol. The cell lysate $(25 \mu \mathrm{l})$ was added to $125 \mu \mathrm{l}$ of ALP reaction buffer (Sigma) and the mixture was incubated at $37^{\circ} \mathrm{C}$ for $30 \mathrm{~min}$. To the mixture, $1 \mathrm{M} \mathrm{NaOH}$ was added to stop the enzymatic reaction. After centrifugation at $16000 \mathrm{~g}$ for $10 \mathrm{~min}, 170 \mu \mathrm{l}$ of supernatant was transferred to a microtiter plate and the absorbance was read at $405 \mathrm{~nm}$ (Erba Chem-7). A calibration line was constructed from different concentrations of $p$-nitrophenol. The ALP activity measured from each sample was related to the cell number in order to calculate the specific ALP activity.

The cell number was calculated by Picogreen ${ }^{\circledR}$ dsDNA Quantitation reagent (Molecular Probes). The cell lysate $(10 \mu \mathrm{l})$ prepared above was mixed with picogreen in trisEDTA buffer $(190 \mu \mathrm{l})$ for $5 \mathrm{~min}$ and the intensity of fluorescence was measured with a multifunction microplate reader (Infinite F200, Tecan) at an excitation and emission wavelength of $485 / 535 \mathrm{~nm}$. Relative fluorescence units were correlated with cell number using a calibration line constructed with increasing concentration of cells.

\subsection{Animal surgical procedures}

The care and management of animals were conducted as per the guidelines of the Institutional Animal Ethics Committee (IAEC) and Committee for the Purpose of Control and Supervision of Experiments on Animals (CPCSEA). Twenty-four Wistar rats with an average body weight of 200-300 g and one defect per leg were divided into four groups: Group I: bare HASi (without cells); Group II: tissue-engineered HASi $(\mathrm{HASi}+\mathrm{C})$; 
Group III: bare HA (without cells); Group IV: tissueengineered $\mathrm{HA}(\mathrm{HA}+\mathrm{C})$.

The surgical procedures were done according to the ISO standard 10993-6. Animals were anesthetized with ketamine $(100 \mathrm{mg} / \mathrm{kg})$ and xylazine $(5 \mathrm{mg} / \mathrm{kg})$ body weight intramuscularly. The skin was shaved and disinfected with betadine-povidone iodine. Longitudinal skin incision to the extent of $1 \mathrm{~cm}$ was made to expose the quadriceps muscle. The materials were then implanted deep into the muscle pouch and the wound was closed with 4.0 mer silk sutures. After closure, the sutured wound was swabbed with betadine and dressed with neosporin. The animals were kept in cages and fed with standard diet and water ad libitum. After 2 and 4 weeks, the animals were euthanized intraperitonially with excess thiopentone sodium. The retrieved tissues were fixed in $10 \%$ neutral buffered formalin in Sorensen phosphate buffer for 2 days and analysed.

\subsection{Evaluation of post-implanted tissues}

2.7a Neo-vascularization studies: The fixed tissues (2 and 4 weeks post-implantation) were decalcified in $5 \%$ formic acid in formalin for 2 days and dehydrated in graded ascending series of acetone and embedded in paraffin. Thin sections $(5 \mu \mathrm{m})$ were made using a microtome (Leica RM 2255). The sections after deparaffinising in xylene were rehydrated in descending grade of ethanol series, stained with hematoxylin, eosin $\mathrm{Y}$ and viewed under light microscope (Leica DM 6000).

\section{7b Neo-osteogenesis studies}

2.7b1 Histological evaluation: The fixed tissues (4 weeks post-implantation) were dehydrated in graded ascending series of isopropyl alcohol and embedded in polymethylmethacrylate (PMMA). The plastic sections of about $100 \mu \mathrm{m}$ were sliced using high-speed precision saw (Isomet $^{\mathrm{TM}} 2000$ Precision Saw, Buehler) and polished to get a thickness of $70-90 \mu \mathrm{m}$. The sections were stained with Stevenal's blue solution for $15 \mathrm{~min}$ at $60^{\circ} \mathrm{C}$ and counter-stained with van Gieson's picrofuchsin for $5 \mathrm{~min}$ at room temperature and viewed under light microscope (Leica DM 6000). Stevenal's blue stains, cells and extracellular structures in shades of blue while van Gieson's picrofuchsin stains collagen fibres (green or green blue), bone (orange or purple) and osteoid matrix (yellow-green) (Maniatopoulos et al 1986).

2.7b2 Histomorphometric analysis: The Stevenal's blue and van Gieson's picrofuchsin stained sections were scanned for determining (a) the area of cells infiltered around and within the pore of the materials and (b) the area of newly formed bone. Five sections were selected randomly and the images were captured with $20 \times$ magni- fication lens and the images were suitably calibrated using an inbuilt image configuration. The area of cells (bluish colour) and the area of newly formed bone (yellowish colour) with respect to the total frame area of image $\left(356911.2 \mu \mathrm{m}^{2}\right)$ was measured using the Quips programme of QWin software of the microscope (Leica DM 6000).

2.7b3 Alkaline phosphatase activity: The fixed tissues (Group II and Group IV - 4 weeks post-implantation) were decalcified in 5\% formic acid in formalin for 2 days and dehydrated in graded ascending series of acetone and embedded in paraffin. Thin sections $(5 \mu \mathrm{m})$ were made using a microtome (Leica RM 2255). The sections were deparaffinised with xylene, rehydrated in descending grade of ethanol series, and permeabilised with $1 \%$ Triton $\mathrm{X}-100$ in PBS for $5 \mathrm{~min}$ and blocked with $3 \%$ BSA in PBS for $30 \mathrm{~min}$. The staining was then performed with ELF 97 endogenous phosphatase detection kit (Invitrogen) for ALP activity and viewed with Hoechst filter of fluorescence microscope (Leica DM 6000).

2.7b4 Mineralization studies: The fixed tissues (Group II and Group IV - 4 weeks post-implantation) were scanned under high-resolution X-ray micro-computed tomography (Micro-CT 40, Scanco Medical, Switzerland) in order to analyse the mineralization of newly formed bone. The scanning parameters used were as follows: slice thickness and slice increment of $12 \mu \mathrm{m}$; energy of $70000 \mathrm{~V}$ and intensity of $114 \mu \mathrm{A}$. The density distribution graphs were plotted from 2D micro-CT images and compared with raw HA and HASi (before implantation).

\subsection{Statistical analysis}

For all in vitro experiments, three separate materials were used ( $n=3$ for HA and $n=3$ for HASi). Again from each material, all measurements were done in duplicate in order to confirm the repeatability. Each parameter was expressed as mean of all values \pm standard deviations. Single factor analysis of variance (ANOVA) was employed to assess the statistical significance of results. $P$-values less than 0.01 were considered significant. For histomorphometric analysis, five sections from four animal models of each group were selected randomly and analysed.

\section{Results}

\subsection{Evaluation of tissue-engineered construct (in vitro)}

The mesenchymal stem cells derived from bone marrow exhibited their characteristic fusiform, spindle-shaped morphology on day 5. The scanning electron micrographs revealed that osteogenic-induced BMSCs attached and 

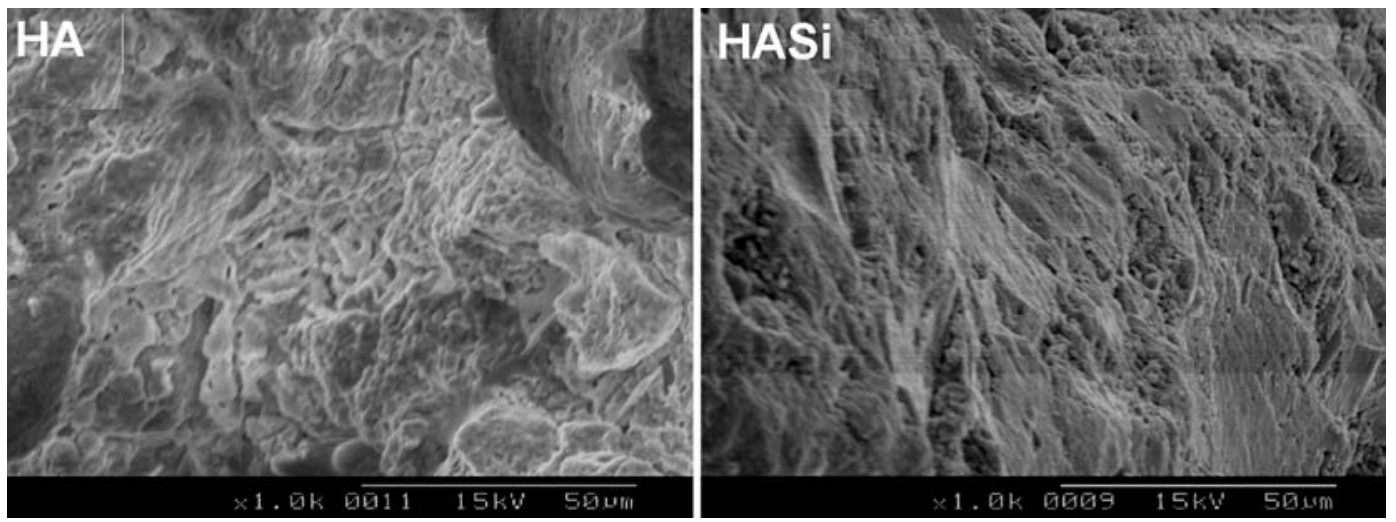

Figure 2. Scanning electron micrographs showing attachment and adhesion of osteogenic-induced rat BMSCs on HA and HASi on day 7.

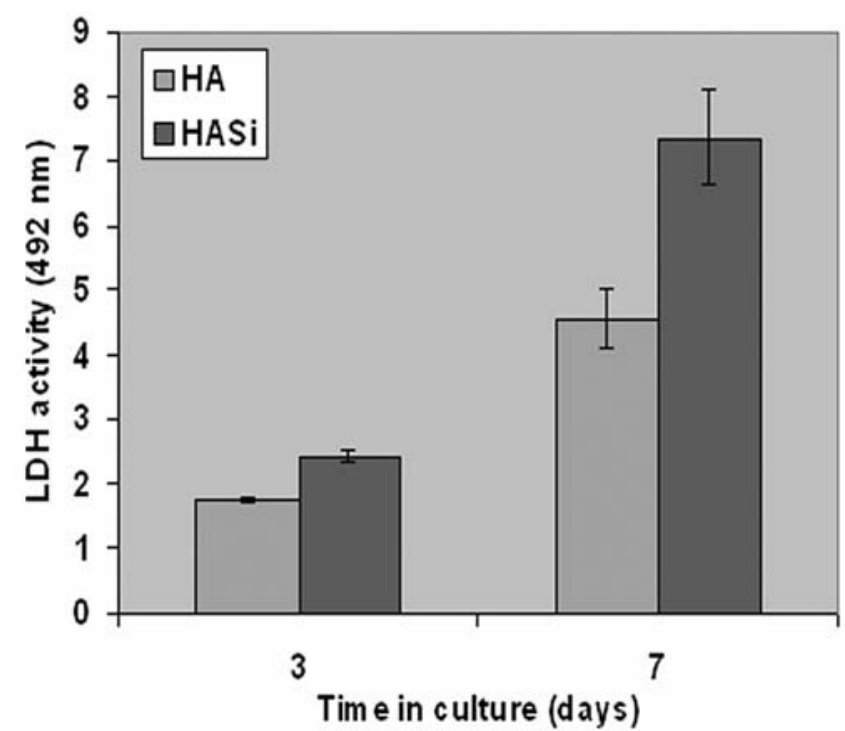

Figure 3. LDH assay for determining viability of osteogenic induced rat BMSCs on HA and HASi (mean \pm standard deviation) $(n=6) . \mathrm{LDH}$ activity was significantly $(P<0 \cdot 001)$ higher on HASi than HA. The $y$-values were calculated after plotting a calibration line with increasing concentration of cells.

adhered on HA and HASi on day 7. The cells on HASi distributed evenly over the material to give a cell sheetlike appearance (figure 2). $\mathrm{LDH}$ assay depicted that the viability of the cells on HA and HASi increased as days increased. While comparing, HASi showed a significant increase in viability on days 3 and 7 (figure 3 ). The specific ALP activity (ALP activity/cell) as a reflection of osteogenic differentiation demonstrated a significant increase in activity on HASi when compared to HA on days 3 and 7 (figure 4).

\subsection{Evaluation of post-implanted tissues}

3.2a Gross view: All rats showed an undisturbed wound healing without any clinical signs of inflammation

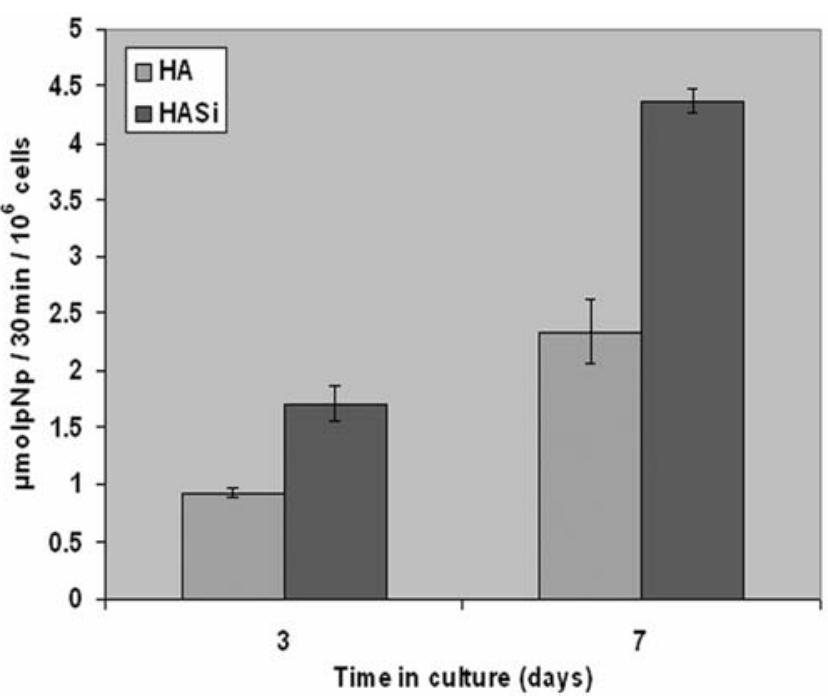

Figure 4. Specific ALP activity of osteogenic-induced rat BMSCs on HA and HASi (mean \pm standard deviation) $(n=6)$. ALP activity was significantly higher on HASi than HA.

at the surgical site. The materials in all the groups showed intimate contact with the surrounding muscles depicting proper stationing of the materials in the implantation bed.

3.2b Neo-vascularisation studies: The ability of materials to facilitate neo-vascularisation at the defect site was determined at 2 and 4 weeks. The vascular invasion was very low in bare HA groups, while a notable increase in blood capillaries together with small blood vessels could be seen in bare HASi groups at 2 weeks (figure 5). At 4 weeks, the vascular invasion with the formation of blood capillaries was improved in bare HA groups. Interestingly, in bare HASi groups, the implantation site was well vascularised with profuse ingrowth of blood capillaries together with numerous thin- and thick-walled blood vessels (figure 6). $\mathrm{HA}+\mathrm{C}$ and $\mathrm{HASi}+\mathrm{C}$ groups showed a prominent increase in performance than bare HA and bare HASi groups at 2 and 4 weeks. 

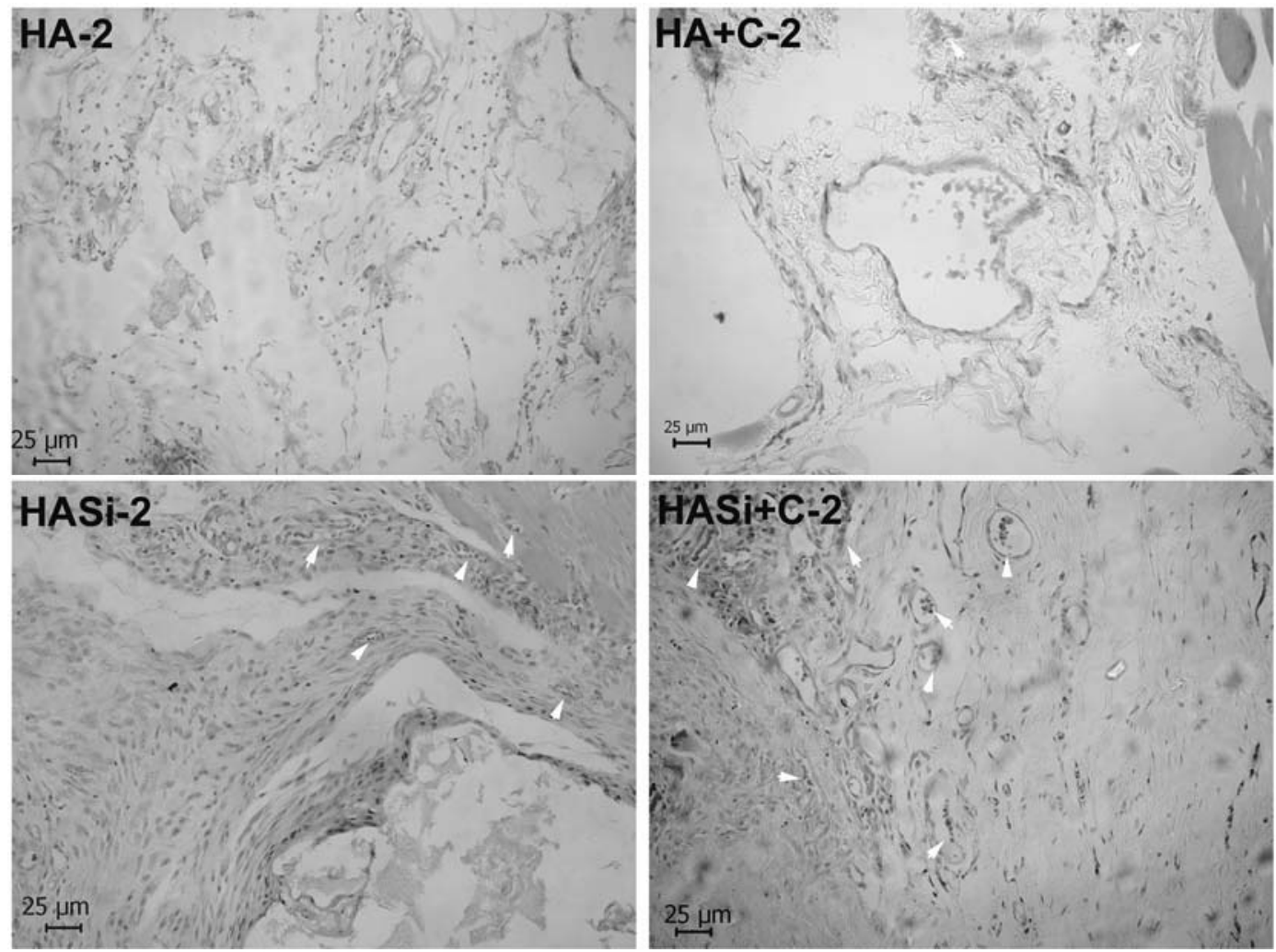

Figure 5. Histological evaluation of neo-vascularization at an extraskeletal site implanted with bare and tissue-engineered $\mathrm{HA} / \mathrm{HASi}-2$ weeks (H\&E staining). Tissue-engineered groups performed better than bare groups, with preference for HASi than HA.

\section{2c Neo-osteogenesis studies}

3.2c1 Histological evaluation: Bare HA and bare HASi groups did not reveal any active site of osteoid deposition or bone mineralization. Bare HA was lined by thin connective tissue of fibroblast-like cells. The majority of osteoblast-like cells was seen along the margin of bare HA and was occasional on the surface or within the pores. However, in bare HASi groups, the cells were visible not only at the periphery but also within the internal pores and on the surface of implant without fibrous tissue formation (figure 7).

A notable difference was seen between tissue-engineered HA and HASi groups. The ingrowth of numerous osteoblast-like cells was seen around and within the pores of the material in $\mathrm{HA}+\mathrm{C}$ groups, but there was no osteoid deposition. Nevertheless, in HASi $+\mathrm{C}$ groups, immature woven bone with osteoblast-like cells infiltered around and within the pores of the material was observed (figure 7).

3.2c2 Histomorphometric analysis: Generally, HASi illustrated an increase in cellular ingrowth as compared to HA, both in bare and tissue-engineered groups. Among the groups, the area of cells infiltered around and within the pores of the materials was in the order of $\mathrm{HA}<$
$\mathrm{HASi}<\mathrm{HASi}+\mathrm{C}<\mathrm{HA}+\mathrm{C}$. There were no significant differences between all these groups except for bare HA groups where the cellular ingrowth was comparatively low. The new bone formation was observed only in HASi $+\mathrm{C}$ groups, which showed that about $30 \%$ of the pores were filled with newly formed bone (figure 8).

3.2c3 Alkaline phosphatase activity: The activity of ALP at the implanted site was observed 2 weeks postimplantation through ELF-97 staining by fluorescence microscopy. $\mathrm{HA}+\mathrm{C}$ and $\mathrm{HASi}+\mathrm{C}$ groups were only included in this study to confirm the histology data concerning new bone formation. The ALP activity was observed in both the groups, with significant enhancement on HASi. Muscle cells taken as negative control showed no ALP activity (figure 9).

3.2c4 Mineralisation studies: The newly formed bone undergoes mineralisation, which was verified through the density distribution graph plotted from 2D micro-CT images 4 weeks post-implantation. $\mathrm{HA}+\mathrm{C}$ and $\mathrm{HASi}+\mathrm{C}$ groups were only included in this study to confirm the histology data concerning new bone formation (figure 10). The density of raw HA and HASi was approximately 2293 and $1657 \mathrm{mgHA} / \mathrm{ccm}$, respectively. Following implantation, $\mathrm{HA}+\mathrm{C}$ groups did not show any 

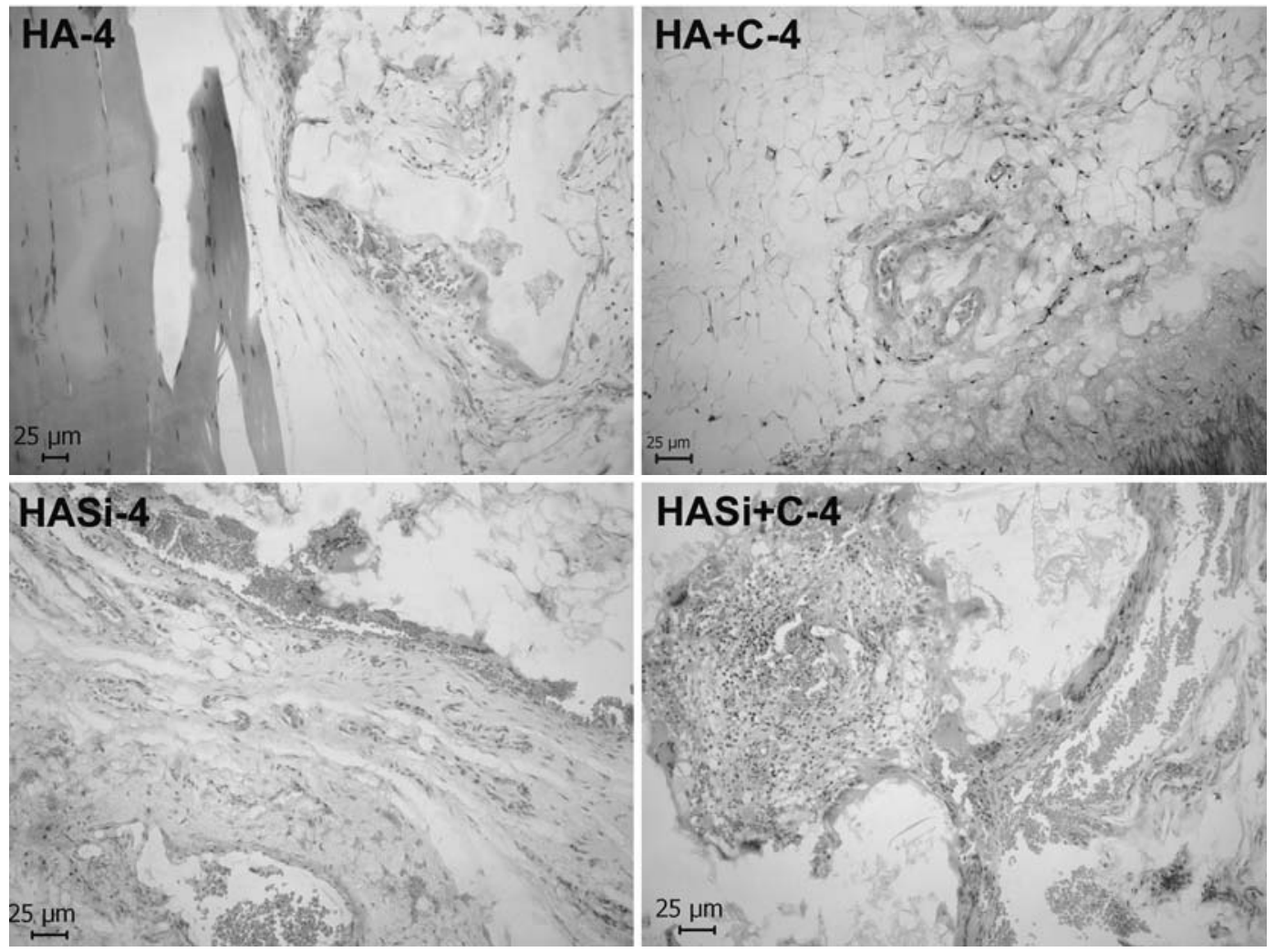

Figure 6. Histological evaluation of neo-vascularization at an extraskeletal site implanted with bare and tissue-engineered HA/HASi - 4 weeks (H\&E staining). Tissue-engineered groups performed better than bare groups, with preference for HASi than HA.
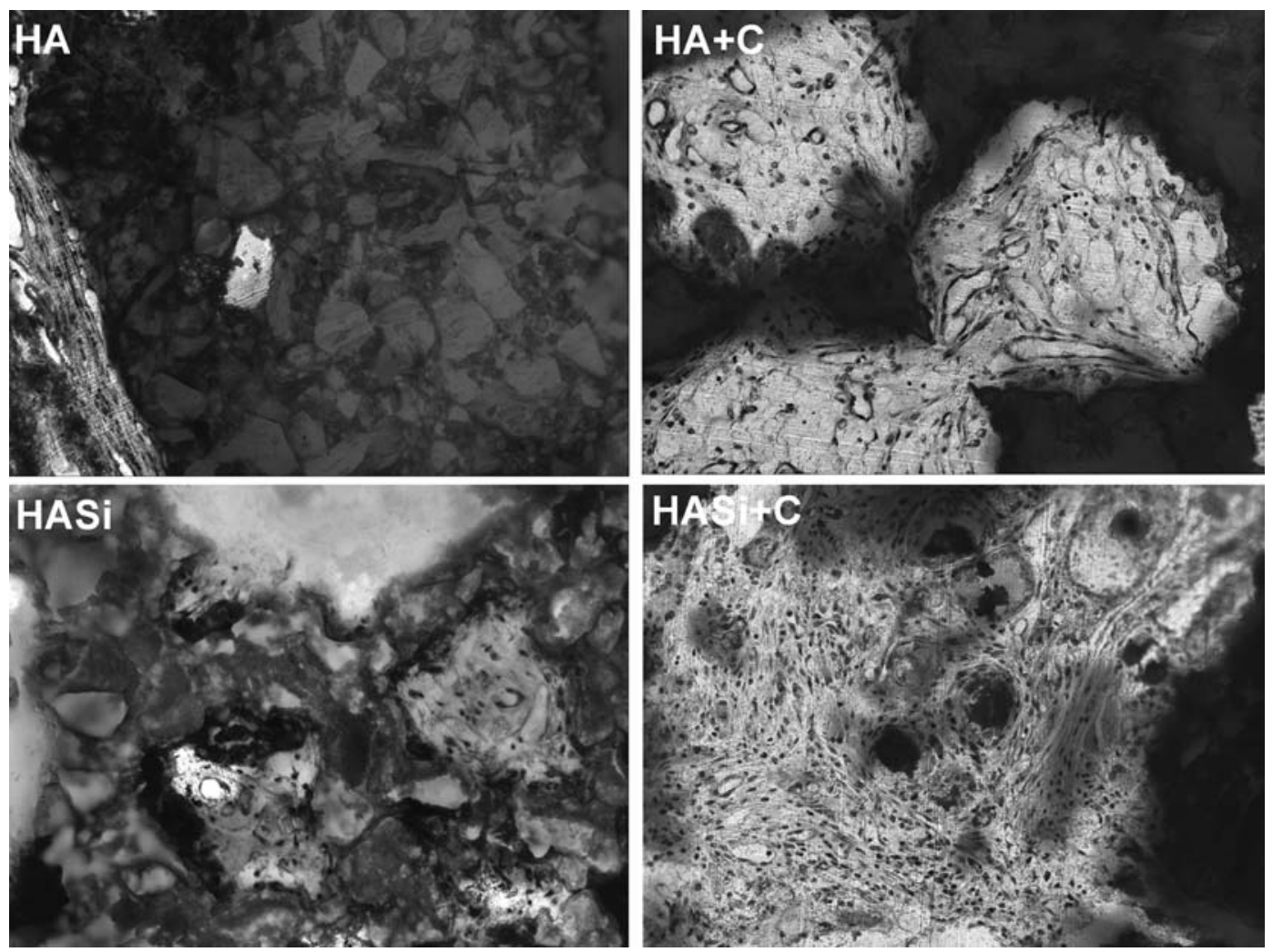

Figure 7. Histological evaluation of neo-osteogenesis at an extraskeletal site - 4 weeks post-implantation. The neo-osteogenesis was seen only in HASi + C groups. Ingrowth of osteoblast-like cells within and around pores of materials was seen in all groups except bare HA groups. 


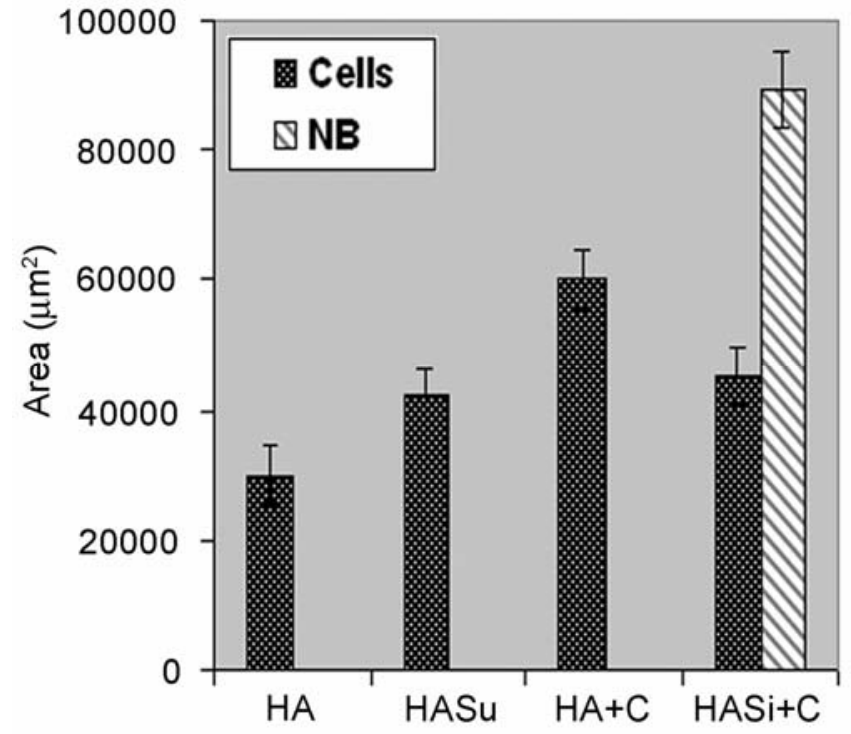

Figure 8. Histomorphometric evaluation of area of cellular infiltration and new bone formation at an extraskeletal site -4 weeks post-implantation. Among the groups, area of cells infiltered around and within pores of materials was in order of $\mathrm{HA}<\mathrm{HASi}<\mathrm{HASi}+\mathrm{C}<\mathrm{HA}+\mathrm{C}$. (NB, new bone.)

remarkable change in the density (approximately $2000 \mathrm{mgHA} / \mathrm{ccm}$ ), while a detectable increase in the density was observed in HASi $+\mathrm{C}$ groups (approximately $2100 \mathrm{mgHA} / \mathrm{ccm}$ ).

\section{Discussion}

Bone has the remarkable capacity to heal without scar formation, but this regenerative process fails in patients with large bone lesions or impaired wound healing, requiring clinical intervention. Due to several problems associated with current therapies and to improve countless lives of patients, the demand for an 'ideal bone graft' for the repair of large bone defects is increased. An ideal bone graft should show (a) biocompatibility, (b) osteoconduction, (c) osteointegration, (d) osteoinduction, (e) osteogenesis and (f) vascularisation. Most of the synthetic materials display many of these properties, except osteoinduction and vascularisation potential, where the process is associated with the presence of growth factors or cells within the graft material. Here comes the importance of tissue-engineering, which utilizes a 3D porous biomaterial with cells and growth factors to provide structural support and to form tissue within the body upon transplantation. Among the triad of tissueengineering (scaffold, cells and growth factors), the selection of scaffold is critical that determines the ultimate success of tissue-engineering. In this study, two materials, viz. hydroxyapatite (HA) and triphasic ceramic-coated hydroxyapatite (HASi), were selected and engineered with osteogenic-induced BMSCs to evaluate its potential to induce neo-vascularisation and neoosteogenesis at an extraskeletal site in rat model. The main difference between $\mathrm{HA}$ and HASi lies in their chemical composition, while the pore size and pore morphology are almost similar. Given the significant roles of $\mathrm{Si}$ in the enhancement of bone growth and development (Pietak et al 2007), HASi was synthesized by incorporating silica on the surface of HA as a coating layer.

The duration of culturing of cells on the materials in vitro prior to implantation is an imperative aspect that ensures the success of tissue-engineered constructs. In some studies, cells were cultured on the scaffolds for few hours, while in other systems, the cells were cultured for one or more weeks before implantation (Kruyt et al 2004). The latter approach is more feasible, which can create an extracellular matrix on the scaffold that provides signals towards the defect site. A previous study with rat BMSCs established that the bone formation was generated more effectively by culturing cells on the scaffold for a short in vitro culture period (days 1-8) (van den Dolder et al 2002). Therefore, a period of 1 week was selected for the fabrication of tissue-engineered constructs. The performance of cells (morphology, viability and osteogenic differentiation) on the scaffolds was examined initially in an in vitro cell culture system to ensure that the cells can attach and proliferate, before being implanted in vivo. HASi provided a favourable platform for cell habitation as compared to HA, which may be due the presence of silica. The surface chemistry of silica-based materials is amenable to very strong irreversible adsorption of serum proteins that can initiate better cell adherence, thereby allowing for increased cell proliferation and differentiation (Messing 1969; Lobel and Hench 1998). Increased viability of rat osteoblasts cultured in the presence of Si compared to that of biphasic calcium phosphate ceramic has been reported (Valerio et al 2005). Another study reported that silica-containing bioactive glass can significantly increase cell proliferation, differentiation and viability of osteoblasts derived from rat calvaria in an in vitro culture condition (Valerio et al 2004). When ROS 17/2.8 cells (rat osteosarcoma cell line) were cultured on porous bioactive glass with $45 \%$ silica, high levels of ALP activity and maintenance of the osteoblastic phenotype was noticed (Kaufmann et al 2000).

The first focus of our study was to evaluate the vascularization potential of bare and tissue-engineered HA as well as HASi. In most cases after transplantation, the cells of tissue-engineered constructs are exposed to the harsh environment of hematoma and may be deprived of vascular supply for weeks, which results in total loss of vitality as all cells require an adequate oxygen supply (Hartman et al 2004). Thus the overall successful application of a bone graft depends not only on the good cellmaterial interactions, but also the sequential growth 

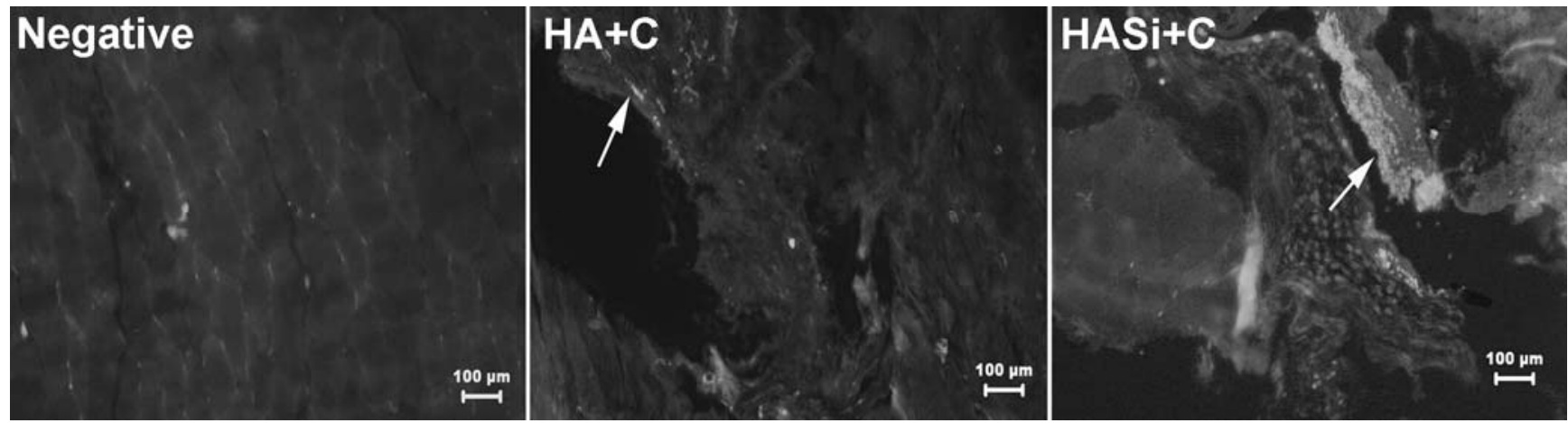

Figure 9. Fluorescent micrographs depicting ALP activity at an extraskeletal site -2 weeks post-implantation. ALP activity was better in HASi $+\mathrm{C}$ than in HA $+\mathrm{C}$ groups. Muscle cells were used as negative control. Staining was performed with ELF-97 for ALP activity (yellowish green).
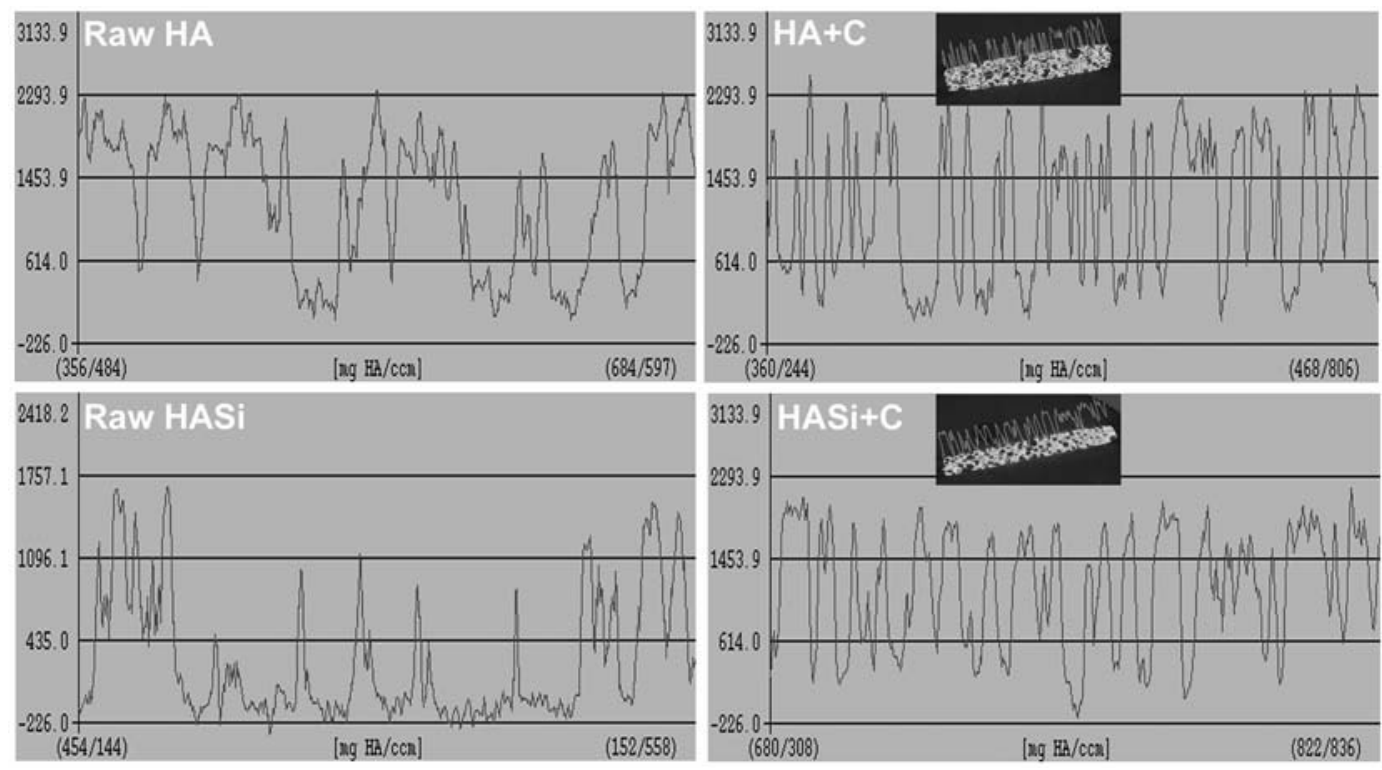

Figure 10. Density distribution graphs (plotted from 2D micro CT image) showing mineralization of newly formed bone at an extraskeletal site -4 weeks post-implantation. $\mathrm{HASi}+\mathrm{C}$ groups showed an increase in density when compared to raw HASi. There was no detectable difference between $\mathrm{HA}+\mathrm{C}$ groups and raw HA. Inset shows $2 \mathrm{D}$ micro-CT image. $\mathrm{mgHA} / \mathrm{ccm}$ denotes milligram of hydroxyapatite per cubic centimetre.

and spread of a vascular system to support the function and maintenance of the regenerated tissue. In vivo, the distance between cells and blood capillaries, which provide nutrients and oxygen and at the same time account for waste elimination, ranges from $20 \mu \mathrm{m}$ to $200 \mu \mathrm{m}$. In vitro, sufficient nutrition and oxygenation of cells by diffusion is limited to a distance of 100-200 $\mu \mathrm{m}$ (Volkmer et al 2008). Thus the scaffold should have appropriate porous structure (pore size above $100 \mu \mathrm{m}$ and interconnected porosity) and chemical composition in order to allow even supply of blood vessels and blood flow within the tissue-engineered constructs. In this study, the highly porous structure of HA and HASi (50-500 $\mu \mathrm{m})$ has facilitated vascular invasion through the materials. Apart from porosity, the chemical composition of scaffolds is also significant, which can be verified through enhanced and quicker (observed at 2 weeks), neo-vascularisation on HASi than HA. One study reported that the increased presence of ionic dissolution products of 45S5 Bioglass (mainly $\mathrm{Si}$ ) can stimulate the expression and release of vascular endothelial growth factor (VEGF) and basic fibroblast growth factor (bFGF) that can induce neo-vascularisation (Richard 2005). In another study, bioactive glass coating with $\mathrm{Si}$ on polymeric substrateenhanced angiogenesis through the mitogenic stimulation of endothelial cells (Leach et al 2006).

The engineering of osteogenic-induced BMSCs on HA and HASi improved neo-vascularisation when compared 
to bare materials (both HA and HASi). The cells cultured on these materials secrete many inductive factors due to their paracrine effects that enhance neo-vascularisation. Among many osteoinductive proteins, the role of ostepontin in angiogenesis is decisive, which mediate endothelial cell migration in cooperation with the upregulation of VEGF (Senger et al 1996; Takahashi et al 2002). Our previous studies with osteogenic-induced goat BMSCs proved the expression of osteopontin on HA and HASi, with better expression on HASi (Nair et al 2008). This may be accountable for enhanced neo-vascularisation in $\mathrm{HA}+\mathrm{C}$ and $\mathrm{HASi}+\mathrm{C}$ groups. The real molecular mechanism has to be elucidated.

The second focus of our study was to evaluate the osteoinductive potential of bare and tissue-engineered HA as well as HASi. The ingrowth of numerous osteoblastlike cells within and around the pore of materials was higher in bare HASi groups and tissue-engineered HA groups (cellular ingrowth was relatively very low in bare HA groups). However, there was no osteoid deposition in those groups. The neo-osteogenesis was shown only by tissue-engineered HASi scaffolds. Histology results are further convinced with ALP activity and micro-CT evaluation. The activity of ALP, a biomarker for bone, peaked significantly on $\mathrm{HASi}+\mathrm{C}$ groups than $\mathrm{HA}+\mathrm{C}$ groups. Similarly, the mineralisation of newly formed bone, confirmed through density distribution graph of 2D micro-CT image, was observed only in HASi $+\mathrm{C}$ groups. It is well recognised that the rate of bone regeneration and its quality is related to porosity (Karageorgiou and Kaplan 2005). When ceramics with different pore sizes were compared, the new bone formation was higher for $300-400 \mu \mathrm{m}$ pore size and this was the critical size above which blood capillaries could be observed when implanted subcutaneously in rats (Tsuruga et al 1997). Even though HA and HASi have similar pore size (50 $500 \mu \mathrm{m})$, new bone formation was observed only in HASi $+\mathrm{C}$ groups. This finding stresses upon the importance of the chemistry of material, mainly the presence of $\mathrm{Si}$ in HASi. A previous study supported this hypothesis where the new bone formation was accelerated when calcium phosphate-calcium silicate system in combination with FG was used at an extraskeletal site of mice model. At the same time, HA did not induce bone formation in the same condition (Abiraman et al 2002). Another study reported that the activity of silica-based bioactive materials can overshadow the effect of even BMP-2 gene therapies and induce local bone turnover (Välimäki et al 2006). Based on this study, we could say that the positive impact in forming bone is attributable to the scaffold (mainly chemistry of material) and the cells, with the first choice for scaffold because both HA and HASi were engineered simultaneously with the cells from the same source and same passage.

The vascularity of the defect site is an important parameter for osteoinduction and for osteogenesis to occur
(Ripamonti 2006). When fresh marrow cells or cultured BMSCs were combined with ceramic as the delivery vehicle, bone was formed in close association with host vasculature (Goshima et al 1991). Hartman et al (2004) found that muscle recipient site could favour bone formation in a cell-based bone graft substitute compared to subcutaneous recipient site due to high vascularity of the muscle tissue. In HASi + C groups, the neo-vascularisation was significantly enhanced and earlier that lead to neoosteogenesis.

The presence of numerous osteoblast-like cells was seen in bare HASi groups, which demonstrates its ability to stimulate the recruitment and proliferation of indigenous stem cells after implantation. Then a question arises: why osteogenesis was not seen with these groups? The tissue-specific differentiation of MSCs is dependent on the local microenvironment in which these cells reside and their interactions with the host tissue. Thus in the absence of any bony environment (extraskeletal site), indigenous cells infiltered towards bare HASi group may need some more time to reach their osteogenic potential to fabricate bone. We anticipate that bare HASi groups may be able to form bone while increasing the implantation period for over 4 weeks. The same results may be obtained with tissue-engineered HA groups, which also showed better infiltration of osteoblast-like cells.

\section{Conclusions}

The osteogenic-induced mesenchymal stem cells together with the favourable phases provided by a triphasic ceramic coated hydroxyapatite (HASi) has accelerated the neovascularisation and bone formation ectopically within a period of 4 weeks in rats. Thus the characteristics of HASi with well-defined porous structure and surface chemistry may be proposed as a bone substitute for the healing of large bone defects which still remains as a clinical challenge in orthopaedic surgery.

\section{Acknowledgements}

The authors acknowledge the Director, SCTIMST for the facilities provided; DRDO for financial assistance; and CSIR for the Senior Research Fellowship for Ms Manitha; Mr Suresh Babu $\mathrm{S}$ for material synthesis; Dr Kalliyana Krishnan for micro-CT evaluation and Mr R Sreekumar for the scanning electron micrographs.

\section{References}

Abiraman S, Varma H K, Umashankar P R and John A 2002 Biomaterials 233023

Burwell R G 1964 J. Bone Joint Surg. B46 110

Caplan A I 1991 J. Orthop. Res. 9641 
Carlisle E M 1970 Science 167279

Goshima J, Goldberg V M and Caplan A I 1991 Biomaterials 12253

Hartman E H, Vehof J W, de Ruijter J E, Spauwen P H and Jansen J A 2004 Biomaterials 255831

Hench L L and Wilson J 1993 An introduction to bioceramics: advanced series in ceramics (USA: World Scientific) Vol 1, pp. 1-24

John A, Nair M B, Bernhardt A, Varma H K and Gelinsky M 2008 Int. J. Appl. Ceram. Technol. 511

Karageorgiou V and Kaplan D 2005 Biomaterials 265474

Kaufmann E A, Ducheyne P and Shapiro I M 2000 J. Biomed. Mater. Res. 52783

Kruyt M C, de Bruijn J D, Wilson C E, Oner F C, van Blitterswijk C A, Verbout A J and Dhert W J 2003 Tissue Eng. 9 327

Kruyt M C, Dhert W J and Oner FC 2004 Transplantation 77 504

Kruyt M C, Dhert W J A, Oner C, van Blitterswijk C A, Verbout A J and de Bruijn J D 2004 J. Biomed. Mater. Res. Part B: Appl. Biomater. B69 113

Leach J K, Kaigler D, Wang Z, Krebsbach P H and Mooney D J 2006 Biomaterials 273249

Lobel K D and Hench L L 1998 J. Biomed. Mater. Res. 39575

Maniatopoulos C, Rodriguez A, Deporter D A and Melcher A H 1986 Int. J. Oral Maxillofac. Implants 131

Messing R A 1969 J. Am. Chem. Soc. 912370

Nair M B, Suresh B S, Varma H K and John A 2008a Acta Biomater. 4173

Nair M B, Bernhardt A, Lode A, Heinemann C, Thieme S, Hanke T, Varma H K, Gelinsky M and John A 2008b J. Biomed. Mater. Res. (Epub ahead of print)
Nair M B, Varma H K and John A 2008 J. Mater. Sci. Mater. Med. 14 Oct (Epub ahead of print)

Pietak A M, Reid J W, Stott M J and Sayer M 2007 Biomaterials 284023

Pittenger M F, Mackay A M, Beck S C, Jaiswal R K, Douglas R, Mosca J D, Moorman M A, Simonetti D W, Craig S and Marshak D 1999 Science 284143

Porter A E, Best S M and Bonfield W 2004 J. Biomed. Mater. Res. A68 133

Richard M D 2005 Tissue Eng. 11768

Ripamonti U 2006 Biomaterials 27807

Salgado A J, Coutinho O P and Reis R L 2004 Macromol. Biosci. 4743

Senger D R, Ledbetter S R, Claffey K P, Papadopoulos-Sergiou A, Peruzzi C A and Detmar M 1996 Am. J. Pathol. 149293

Takahashi F, Akutagawa S, Fukumoto H, Tsukiyama S, Ohe Y, Takahashi K, Fukuchi Y, Saijo N and Nishio K 2002 Int. J. Cancer 98707

Takahashi Y, Yamamoto M and Tabata Y 2005 Biomaterials 26 3587

Tsuruga E, Takita H, Itoh H, Wakisaka Y and Kuboki Y 1997 J. Biochem. 121317

Valerio P, Guimaraes M H, Pereira M M, Leite M F and Goes A M 2005 J. Mater. Sci. Mater. Med. 16851

Valerio P, Pereira M M, Goes A M and Leite M F 2004 Biomaterials 252941

Välimäki V V and Aro H T 2006 Scand. J. Surg. 9595

van den Dolder J, Vehof J W, Spauwen P H and Jansen J A 2002 J. Biomed. Mater. Res. 62350

Volkmer E, Drosse I, Otto S, Stangelmayer A, Stengele M, Kallukalam B C, Mutschler W and Schieker M 2008 Tissue Eng. A14 1331 